\title{
Effect of dialysis on plasma and CSF tryptophan and CSF 5-hydroxyindoleacetic acid in advanced renal disease
}

\author{
PATRICK A SULLIVAN, D MURNAGHAN, N CALlAGHAN, B D KANTAMANENi, \\ AND G CURZON \\ From the University Department of Medicine and the Department of Neurology, Cork Regional Hospital, \\ Wilton, Cork, Ireland, and the Department of Neurochemistry, Institute of Neurology, London
}

SUMMARY Patients with uraemic encephalopathy were previously found to have low total tryptophan (bound plus free), but high free tryptophan concentrations in the plasma and high CSF tryptophan concentrations. The 5-hydroxytryptamine metabolite 5-hydroxyindoleacetic acid was also raised in the CSF. A study of the effect of dialysis treatment on these substances in chronic uraemic patients with and without dialysis dementia is described. After an episode of dialysis the patients without dialysis dementia showed increased plasma total tryptophan and decreased free tryptophan. These changes were associated with a decrease of plasma free fatty acid. The patients with dialysis dementia did not show changes in tryptophan, but plasma free fatty acid rose. CSF concentrations of 5-hydroxyindoleacetic acid fell moderately in both groups of patients on dialysis.

The syndrome of chronic uraemia consists of complex abnormalities which, in advanced cases, affect virtually all systems in the body. Uraemic encephalopathy is one of its manifestations and includes asterixis, mental deterioration, tremor, myoclonic and other convulsions, and coma. ${ }^{1}$ We recently confirmed ${ }^{2}$ the reduced plasma total (bound plus free) tryptophan concentration and the weakened binding of tryptophan to plasma albumin reported previously in uraemia, ${ }^{34}$ and found that patients with uraemic encephalopathy had raised plasma free tryptophan and CSF tryptophan concentrations. As the 5-hydroxytryptamine (5HT) metabolite 5-hydroxyindoleacetic acid (5HIAA) also was raised in the CSF of these subjects, the results suggested an increase in brain 5HT turnover in uraemic encephalopathy due, at least in part, to increased availability to the brain of the 5HT precursor tryptophan. Direct determinations on post-mortem brain material ${ }^{5}$ are consistent with our findings and point to a possible role for abnormal brain $5 \mathrm{HT}$ metabolism in uraemic encephalopathy.

Symptoms of uraemic encephalopathy disappear following haemodialysis but dialysis

Address for reprint requests: Professor G Curzon, Department of Neurochemistry, Institute of Neurology, 33 John's Mews, London WC1N 2NS.

Accepted 14 April 1980 dementia may occur. ${ }^{6}$ In the present paper we studied patients under dialysis treatment for chronic uraemia with and without dialysis dementia. Plasma tryptophan (total and free) and CSF tryptophan were measured and also plasma free fatty acid (FFA) as these latter substances decrease the binding of tryptophan to plasma albumin $^{7} 8$ making the amino acid more available to the brain. ${ }^{9-11}$

\section{Patients and methods}

Fifteen patients on a chronic dialysis programme were studied after approval had been obtained from the hospital Ethics Committee and the procedure had been explained to all subjects. None of the subjects were taking drugs known to influence the metabolism or disposition of brain 5HT or dopamine. Five of the patients (all male) had the dialysis dementia syndrome with EEG abnormalities (high voltage delta waves, spike activity, generalised slowing), multiple seizures, dysarthria, speech absences and progressive mental deterioration. They had been on a dialysis programme for longer than the group without dementia (table 1). Before the start of each dialysis episode the patients were given 7500-10000 IU heparin and a booster dose of 2500-5000 IU 2.5 hr later. Heparin doses given 
Table 1 Clinical details of patients

\begin{tabular}{llll}
\hline & Age & $\begin{array}{l}\text { Years on } \\
\text { dialysis }\end{array}$ & $\begin{array}{l}\text { Hours of last } \\
\text { dialysis }\end{array}$ \\
\hline $\begin{array}{l}\text { Controls* (10M, 9F) } \\
\begin{array}{l}\text { Uraemic patients } \\
\text { Encephalopathy. Not on } \\
\text { dialysis programme1 }\end{array}\end{array}$ & $50 \pm 15$ & 0 & 0 \\
$\begin{array}{l}\text { (3M, 4F) } \\
\text { Dialysis without dementia }\end{array}$ & $50 \pm 16$ & 0 & 0 \\
$\begin{array}{l}\text { (3M, 7F) } \\
\begin{array}{l}\text { Dialysis with dementia } \\
(5 \mathrm{M})\end{array}\end{array}$ & $35 \pm 15$ & $2 \cdot 4 \pm 1.6$ & $6.3 \pm 1.4$ \\
\hline
\end{tabular}

*From reference 2.

Values given as means \pm one SD with number of patients in brackets Difference from corresponding group without dementia: $\dagger p<0.01$.

varied approximately with patient weight. Lumbar CSF and blood were collected from subjects who were fasted overnight. Samples were taken between 0900 and $1000 \mathrm{hr}$ immediately before dialysis $(10 \mathrm{~min}$ after heparin injection) and also 5 to $8 \mathrm{hr}$ later at the end of dialysis periods. The intervals between withdrawal of CSF and blood were less than $10 \mathrm{~min}$. Blood was also taken from five of the nondemented patients immediately before the first heparin injection.

Blood samples were collected into cold heparinised tubes and immediately centrifuged. Plasma and CSF were frozen at $-20^{\circ} \mathrm{C}$. Plasma tryptophan (total and free), FFA, albumin, CSF tryptophan and 5HIAA were determined as previously described. ${ }^{2}$ Results were compared with previous findings ${ }^{2}$ on a control group with normal renal function who were undergoing lumbar punctures as part of their neurological investigations. None of these patients was suffering from disturbances known to alter cerebral transmitter metabolism.

\section{Results}

Effect of heparin on plasma FFA and tryptophan binding Routine administration of heparin before and during dialysis can lead to high plasma lipoprotein lipase activity and hence high plasma free fatty acid concentrations. Thus ten minutes after giving heparin dosages comparable to those given before the dialysis procedure the plasma FFA was apparently $500 \%$ elevated. ${ }^{12}$ These large increases were not found in the present study as mean free fatty acid rose by only $65 \%$ (table 2 ), a rise which was not statistically significant. Plasma total and free tryptophan concentrations were also negligibly affected. The small magnitude of the changes may have resulted from the taking of precautions to avoid artefactual in vitro lipolysis. ${ }^{13}$
Table 2 Plasma concentrations of tryptophan and free fatty acids (FFA) in endstage uraemic patients before and after heparin iniection

\begin{tabular}{|c|c|c|c|c|}
\hline & \multicolumn{2}{|l|}{ Tryptophan } & \multirow[t]{2}{*}{$\%$ Free } & \multirow[t]{2}{*}{$F F A \quad m E Q / 1$} \\
\hline & Total ug/ml & Free ug $/ \mathrm{ml}$ & & \\
\hline $\begin{array}{l}\text { Before } \\
\text { heparin } \\
10 \text { min } \\
\text { after hep } \\
\text { parin, } \\
\text { Before }\end{array}$ & $6.54 \pm 0.67(5)$ & $1 \cdot 74 \pm 0.30$ & $26 \cdot 9 \pm 5 \cdot 9$ & $0.49 \pm 0.35$ \\
\hline $\begin{array}{l}\text { dialysis } \\
\text { p(paired } \\
\text { test) }\end{array}$ & $\begin{array}{l}6.41 \pm 0.96(5) \\
\mathrm{ns}\end{array}$ & $\begin{array}{l}1.92 \pm 0.45(5) \\
\text { ns }\end{array}$ & $\begin{array}{l}30 \cdot 1 \pm 8 \cdot 0(5) \\
\text { ns }\end{array}$ & $\begin{array}{l}0.81 \pm 0 \cdot 16(5) \\
\text { ns }\end{array}$ \\
\hline
\end{tabular}

Values given as means \pm one SD with number of patients in brackets. No patients had dialysis dementia.

Plasma tryptophan concentration and binding in uraemia: effect of dialysis Table 3 shows mean values of plasma total and free tryptophan, free fatty acid and albumin concentrations of uraemic patients with and without dialysis dementia before and immediately after a period of dialysis. Plasma total tryptophan concentrations were markedly low before an episode of dialysis, especially in the demented group. The dialysis period was followed by a rise of plasma total tryptophan concentration in the non-demented group only, though values attained were still below those of the controls.

Although plasma free tryptophan concentration in the dialysed groups before an episode of dialysis was not higher than in the controls its percentage in the free form was very high. Both absolute and percentage values fell in the nondemented group after dialysis, to become comparable to control values, but corresponding values for the three demented subjects on whom free tryptophan was determined were not decreased by dialysis.

The very high percentage free tryptophan values in uraemia were associated with normal free fatty acid concentrations and only slightly decreased albumin concentrations. ${ }^{2}$ However, the fall of percentage free tryptophan shown by the non-demented subjects after an episode of dialysis was associated with a fall of free fatty acid concentration. The demented patients (whose percentage free tryptophan values did not fall on dialysis) exhibited a considerable rise of free fatty acid. Intermediate results were obtained on plasma taken from one of these patients at an earlier stage of dementia and also on a female patient not included in tables 3 and 4 with early dementia (FFA, $-19 \%,+2 \%$ respectively). These patients had minimal behavioural signs of dialysis dementia although EEG findings were compatible with this diagnosis. 
Table 3 Plasma concentrations of tryptophan and related substances in endstage uraemics on dialysis programme

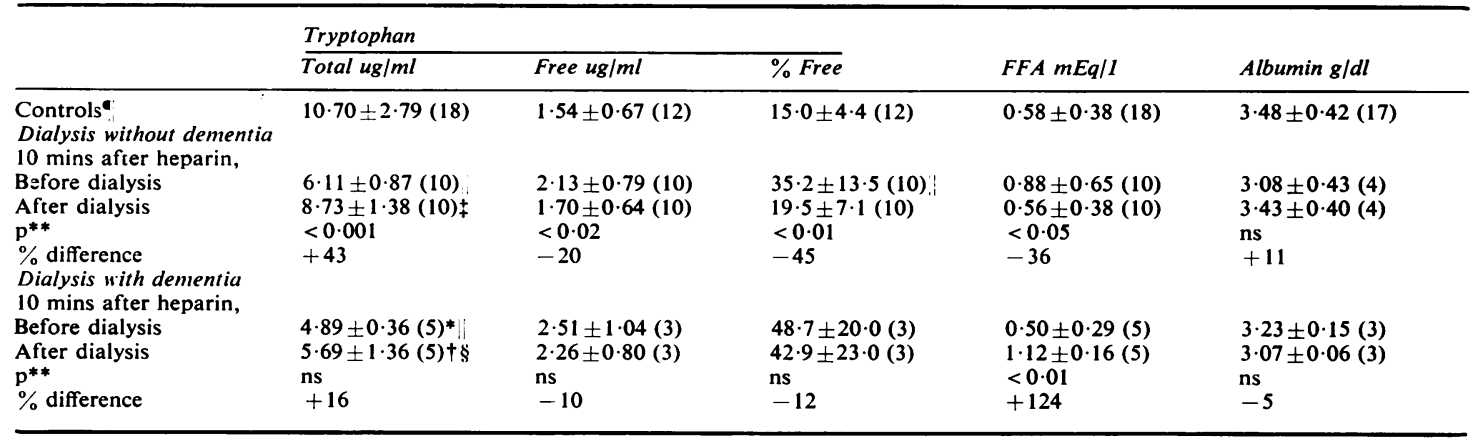

Values given as means \pm one SD with number of patients in brackets.

Difference from corresponding group without dementia: ${ }^{*} \mathrm{p}<0.02+\mathrm{p}<0.01$ (unpaired $t$ test).

Difference from controls: $\ddagger p<0.05 \$ p<0.01 \|<0.001$ (unpaired $t$ test).

- From reference 2 .

**Paired $t$ test (determinations before and after dialysis on same subjects).

Table 4 CSF concentrations of tryptophan and 5-hydroxyindoleacetic acid $(5 H I A A)$ in endstage uraemic patients

\begin{tabular}{lll}
\hline & Tryptophan ug/ml & 5HIAA ug/ml \\
\hline $\begin{array}{l}\text { Controls* } \\
\text { Dialysis without dementia }\end{array}$ & $0.41 \pm 0.11(13)$ & $0.023 \pm 0.017(13)$ \\
$\begin{array}{l}\text { Before dialysis } \\
\text { After dialysis }\end{array}$ & $0.43 \pm 0.12(4)$ & $0.035 \pm 0.013(4)$ \\
p $\dagger$ & $0.35 \pm 0.11(4)$ & $0.026 \pm 0.011(4)$ \\
$\%$ difference & $n s$ & $<0.02$ \\
$\begin{array}{l}\text { Dialysis with dementia } \\
\text { Before dialysis }\end{array}$ & -19 & -26 \\
$\begin{array}{l}\text { After dialysis } \\
\text { p } \dagger\end{array}$ & $0.53 \pm 0.12(3)$ & $0.039 \pm 0.014(3)$ \\
$\%$ difference & $0.48 \pm 0.12(3)$ & $0.032 \pm 0.012(3)$ \\
\hline
\end{tabular}

*From reference 2 .

Values given as means \pm one SD with number of patients in brackets. †Paired $t$ test (determinations before and after dialysis on same subjects).

Amine precursors and metabolites in CSF Table 4 gives mean values of CSF tryptophan and 5HIAA for the groups of subjects described above. Mean 5HIAA concentrations of patients on dialysis programmes before an episode of dialysis were above those of the control group, although differences were not statistically significant. After an episode of dialysis 5HIAA, but not tryptophan, concentrations fell slightly in both dialysed groups, the mean values for the non-demented group becoming comparable to the control values.

\section{Discussion}

The reduced binding of plasma tryptophan previously found in undialysed uraemic patients $^{24}$ was also apparent in material from uraemic subjects on dialysis programmes taken immediately before an episode of dialysis. Albumin is responsible for the binding of trypto- phan in plasma and free fatty acid is able to weaken this in uraemic and normal subjects alike. $^{2} 8$ However, the reduced binding in uraemia is explicable neither by increased free fatty acid nor by decreased albumin concentration. ${ }^{2}$ It has been suggested that an unknown competing substance is responsible for the decreased binding 4 although electrophoretic evidence points to an abnormality of the albumin molecule. 1415

An episode of dialysis resulted in a marked and significant trend towards a return to normal of tryptophan binding in the non-demented subjects. The decrease of plasma free fatty acid which also occurred may have been partly responsible for this, and for the associated increase of plasma total tryptophan concentration. The latter values were still somewhat below control levels, which perhaps reflects the moderate fall of plasma total tryptophan reported after some months of chronic dialysis. ${ }^{16}$ However, the suggestion ${ }^{16}$ that psychiatric consequences of dialysis might be explained by a resultant brain tryptophan deficiency seems unlikely as evidence indicates that brain tryptophan concentrations parallel not plasma total, but plasma free tryptophan concentration ${ }^{9-11} 17$ and this did not differ from control values in either group of dialysed subjects. Similarly, CSF tryptophan values were normal.

The small group of patients with dialysis dementia (unlike the non-demented group) did not show any change of plasma tryptophan binding after a dialysis episode even though the considerable rise of free fatty acid concentration might have been expected to weaken tryptophan binding further. This absence of a major 
change of binding suggests that dialysis concurrently removed other material from the plasma which had weakened tryptophan binding. ${ }^{4}$

Increase of plasma free fatty acid on dialysis has been suggested to reflect either the activation of lipoprotein lipase by administered heparin ${ }^{12}$ or lipolysis provoked by the stress of dialysis. ${ }^{18}$ As heparin dosages and dialysis times were similar for both groups of patients the present results are explicable by a greater lipolytic response to heparin, a greater effect of stress on lipolysis, or defective catabolism of the free fatty acid generated by lipolysis in the demented patients. It is unclear whether the different effects of dialysis on plasma free fatty acid concentration in the two groups is related to the presence or absence of dementia or to the greater period the demented group had been on a dialysis programme.

Both the non-demented and demented subjects showed significant and comparable decreases of CSF 5HIAA after a dialysis episode. As studies on diurnal CSF 5HIAA in normal subjects suggest either increased $^{19}$ or unaltered $^{10}$ concentrations over a corresponding period, the present findings are consistent with a decrease of brain 5HT synthesis on dialysis though increased egress of 5HIAA from the CSF is not excluded.

Raised brain 5HT synthesis in undialysed uraemic patients ${ }^{2} 5$ and its decrease by dialysis, which opposes uraemic encephalopathy, may appear inconsistent with the alleviation of uraemic myoclonus by clonazepam ${ }^{20}$ as this drug is used in the treatment of post-anoxic myoclonus where decreased brain 5HT synthesis appears to have a causal role. ${ }^{21}$ However, the relationship between the effects of clonazepam on myoclonus and on serotoninergic systems is uncertain. ${ }^{22}$ Indeed, as it alleviates not only post-anoxic myoclonus but also DDT myoclonus ${ }^{23}$ where 5HT synthesis is increased its therapeutic action may well not occur through an effect on 5HT containing systems.

We thank the Medical Research Council for a programme grant to $\mathbf{G}$ Curzon and the Medical Research Council of Ireland for a grant to PA Sullivan.

\section{References}

1 Tyler HR. Neurological disorders in renal failure. Am J Med 1968; 44:734-48.

2 Sullivan PA, Murnaghan D, Callaghan N, Kantamaneni BD, Curzon G. Cerebral trans- mitter precursors and metabolites in advanced renal disease. J Neurol Neurosurg Psychiatry 1978; 41:581-8.

3 Gulyassy PF, Peters JH, Lin SC, Ryan PM. Hemodialysis and plasma aminoacids composition in chronic renal failure. Am J Clin Nutr 1978; 21:565-73.

4 De Torrente A, Glazer GB, Gulyassy P. Reduced in vitro binding of tryptophan by plasma in uraemia. Kidney Int 1974; 6:222-9.

5 Jellinger K, Riederer P, Kleinberger G, Wuketich $\mathbf{S}$, Kothbauer $\mathbf{P}$. Brain monoamines in human hepatic encephalopathy. Acta Neuropath (Berl) 1978; 43:63-8.

6 Alfrey AC, LeGendre GR, Kaehny WD. The dialysis encephalopathy syndrome: possible aluminium intoxication. $N$ Engl J Med 1976; 294: 184-8.

7 McMenamy RH. Binding of indole analogues to human serum albumin. Effect of fatty acids. J Biol Chem 1965; 240:4235-43.

8 Curzon G, Friedel J, Kantamaneni BD, Greenwood MH, Lader MH. Unesterified fatty acids and the binding of tryptophan in human plasma. Clin Sci Mol Med 1974; 47:415-24.

9 Knott PJ, Curzon G. Free tryptophan in plasma and brain tryptophan metabolism. Nature 1974; 239:452-3.

10 Young SN, Lal S, Feldmuller F et al. Parallel variation of ventricular CSF tryptophan and free serum tryptophan in man: $J$ Neurol Neurosurg Psychiatry 1976; 31:61-5.

11 Curzon G. Relationships between plasma, CSF and brain tryptophan. J Neurol Transm (Suppl) 1979; 15:81-92.

12 Dromgoole SH. The binding capacity of albumin and renal disease. J Pharmacol Ther 1974; 191: 318-23.

13 Hutson PH, Knott PJ, Curzon G. Control ef brain tryptophan in rats on a high fat diet. Nature 1976; 262:142-3.

14 Boobis SW. Alteration of plasma albumin in relation to decreased drug binding in uremia. Clinical Pharmacol Ther 1977; 22:147-53.

15 Shoeman DW, Azarnoff DL. The alteration of plasma proteins in uremia as reflected in their ability to bind digitoxin and diphenyl hydantoin. Pharmacology 1972; 7:169-77.

16 Unge G, Lins E, Hultman E. Tryptophan in patients on chronic haemodialysis. Lancet 1977; 2:937.

17 Bloxam DL, Tricklebank MD, Patel AJ, Curzon G. Effects of albumin, amino acids and clofibrate on the uptake of tryptophan by the rat brain. J Neurochem 1980; 34:43-9.

18 Anton AH, Corey WT. Interindividual differences in the protein binding of sulphonamides. The effect of disease and drugs. Acta Pharmacol Toxicol (Copenh) 1971; 29 Suppl. 3:134-51.

19 Nicoletti F, Cambria A, Raffaele R, Grasso AM. Falsaperla A. Determinazione circadiana dell' acido 5-idrossi-indolacetico nel liquido cerebro- 
spinale umano. Bol Soc Biol Sper 1978; 54: 497-502.

20 Chadwick D, French AT. Uraemic myoclonus: an example of reticular reflex myoclonus. $J$ Neurol Neurosurg Psychiatry 1979; 42:52-5.

21 Chadwick D, Hallet $M$, Harris $\mathbf{R}$, Jenner $\mathbf{P}$, Reynold EH, Marsden CD. Clinical, biochemical and physiological factors distinguishing myoclonus responsive to 5-hydroxytryptophan, trypto- phan plus a monoamine oxidase inhibitor, and clonazepam. Brain 1977; 100:455-87.

22 Pratt J, Jenner P, Reynolds EH, Marsden CD. Clonazepam induces decreased serotonergic activity in the mouse brain. Neuropharmacology 1979; 18:791-9.

23 Hwang EC, Van Woert MH. pp'-DDT-induced neurotoxic syndrome: experimental myoclonus. Neurology (Minneap) 1978; 28:1020-5. 